\title{
Roles of extracellular matrix in follicular development
}

\author{
R. J. Rodgers, I. L. van Wezel, H. F. Irving-Rodgers, T. C. \\ Lavranos, C. M. Irvine and M. Krupa \\ Department of Medicine, Flinders University of South Australia, Bedford Park, \\ South Australia 5042, Australia
}

\begin{abstract}
The cellular biology and changes in the extracellular matrix of ovarian follicles during their development are reviewed. During growth of the bovine ovarian follicle the follicular basal lamina doubles 19 times in surface area. It changes in composition, having collagen IV $\alpha 1-26$ and laminin $\alpha 1, \beta 2$ and $\gamma 1$ at the primordial stage, and collagen IV $\alpha 1$ and $\alpha 2$, reduced amounts of $\alpha 3-\alpha 5$, and a higher content of laminin $\alpha 1$, $\beta 2$ and $\gamma 1$ at the antral stage. In atretic antral follicles laminin $\alpha 2$ was also detected. The follicular epithelium also changes from one layer to many layers during follicular growth. It is clear that not all granulosal cells have equal potential to divide, and we have evidence that the granulosal cells arise from a population of stem cells. This finding has important ramifications and supports the concept that different follicular growth factors can act on different subsets of granulosal cells. In antral follicles, the replication of cells occurs in the middle layers of the membrana granulosa, with older granulosal cells towards the antrum and towards the basal lamina. The basal cells in the membrana granulosa have also been observed to vary in shape between follicles. In smaller antral follicles, they were either columnar or rounded, and in follicles $>5 \mathrm{~mm}$ the cells were all rounded. The reasons for these changes in matrix and cell shapes are discussed in relation to follicular development.
\end{abstract}

\section{Introduction}

The mammalian ovary produces mature oocytes capable of being fertilized and sustaining embryonic development. It also produces steroid hormones which primarily communicate to the other organs the degree of progress in the development of the oocyte, both before and after ovulation. These functions are accomplished by follicles and corpora lutea. Follicles contain an epithelioid layer, the membrana granulosa, surrounded by a basal lamina which in turn separates it from the surrounding stroma (preantral follicles) or the theca interna (antral follicles). At ovulation, the epithelioid granulosal cells redifferentiate into the mesenchymal luteal cells.

Compared with other organs, very little is known about the cellular biology of developing follicles. Even some of the most basic cellular biology has not been described for this structure. The aim of this review is to focus on some of our new ideas and discoveries that relate particularly to the extracellular matrix, including the follicular basal lamina. The development of the membrana granulosa is also considered, and comparisons to other epithelia are made where appropriate.

\section{Extracellular Matrix}

The extracellular matrix, more aptly termed intercellular matrix, has many different roles, including effects on cell behaviour, such as migration, division, differentiation, cell death and cell anchorage. 
The extracellular matrix can play a role in the fluid dynamics of a tissue, either providing osmotic forces, or filtering material from solutions as they pass through the matrix. They can provide mechanical support for tissues, either rigid or elastic. In addition, nutritional materials and hormones and other extracellular signals are often required to traverse the extracellular matrix to reach target cells. The extracellular matrix can bind growth factors, either directly or indirectly via the specific binding proteins for the growth factors, ensuring that they act locally. In essence the extracellular matrix defines and provides microenvironments, enabling cells to specialize. Not surprisingly extracellular matrix is generally a diverse mixture of components.

There are a number of different compartments and extracellular matrices in follicles. These include the follicular basal lamina, follicular fluid, zona pellucida, membrana granulosa, cumulus, and either theca interna and theca externa in larger antral follicles, or the stroma in the smaller primordial and preantral follicles. These matrices have been studied to various degrees. The study of the zona pellucida is well advanced and has been reviewed many times; the production of hyaluronin by cumulus cells has also been well studied. Follicular fluid has been analysed for its composition of glycosaminoglycans (GAGs: Yanagishita et al., 1979; Bellin and Ax, 1984; Grimek, 1984) and the biochemical production of the GAGs by granulosal cells has been studied by Yanagishita and colleagues. However, very little attention has been paid to the proteoglycans from which the GAGs were derived, or their physiological roles. The mesenchymal area surrounding the membrana granulosa has not been the focus of systematic study, which is unfortunate as the phenotype of the cells changes as follicular development occurs from stroma to theca.

\section{Basal Lamina}

Basal laminae are specialized sheets of extracellular matrix that separate epithelial cell layers from underlying mesenchyme in organs throughout the body including the ovary. They influence epithelial cell migration, proliferation and differentiation, and can selectively retard the passage of molecules from one side of a basal lamina to the other. Basal laminae are a lattice-type network of collagen IV intertwined with a network of laminin. This structure is stabilized by the binding of entactin to the collagen and laminin, and by low-affinity interactions between collagen IV and laminin (Yurchenco and Schittny, 1990; Paulsson, 1992). Fibronectin, heparan sulphate proteoglycans (HSPGs) and other molecules are associated with the collagen IV-laminin backbone. Importantly, basal laminae in different regions of the body differ in the ratio of all these components. Furthermore, each 'component' is in effect a class of several components. Thus each collagen IV molecule is composed of three $\alpha$ chains, but six different types of $\alpha$ chain have been discovered to date. Potentially, any combination of these might be present (Hay, 1991; Zhou et al., 1994). Similarly, each laminin molecule is composed of one $\alpha$. (A in the old nomenclature), one $\beta$ (B1 in the old nomenclature) and one $\gamma$ (B2 in the old nomenclature) chain (Burgeson et al., 1994), yet five different $\alpha$ chains, three $\beta$ chains and two $\gamma$ chains have been discovered. There are at least twenty different isoforms of fibronectin, due to alternative splicing of mRNA. It is considered that the unique composition of each basal lamina contributes to its specific functional properties (Engvall, 1993).

Numerous studies in vitro have shown that cell morphology was altered according to the type of extracellular matrix component on which the cells were cultured (Watt, 1986). Thus alterations to the composition of the basal lamina may affect the fate of the associated cells. The composition of basal laminae also affects their ability to filter materials selectively. For example, in the normal neonatal mouse, laminin $\beta 1$ is replaced by $\beta 2$ in the kidney glomerular basement membrane as the kidney develops. However, mice with a null mutation in the laminin $\beta 2$ gene continued with $\beta 1$, but then failed to retard the passage of plasma proteins across the glomerular basement membrane, despite the membrane being structurally intact. These mice died of proteinurea within one month of birth (Noakes et al., 1995).

In ovarian follicles there are many different basal laminae including the follicular basal lamina. The vasculature of the theca has a subendothelial basal lamina, and the smooth muscle cells of the arterioles have basal laminae. 


\section{Follicular Basal Lamina}

In the ovary, the membrana granulosa of each ovarian follicle is enveloped by a follicular basal lamina, which separates it from the surrounding stromal elements in primordial follicles (van Wezel and Rodgers, 1996) or from the theca in antral follicles (Gosden et al., 1988; Luck, 1994). The follicular basal lamina is believed to play a tole in influencing granulosal cell proliferation and differentiation (Amsterdam et al., 1989; Richardson et al., 1992; Luck, 1994). In addition, in healthy follicles it excludes capillaries, white blood cells and nerve processes from the granulosal compartment until ovulation, at which time the basal lamina is degraded.

The follicular basal lamina probably has a role in retarding entry of larger molecular weight plasma proteins and molecules (for example low density lipoproteins, LDL) into the follicular antrum (Andersen et al., 1976). Conversely if the flow of material in the other direction is similarly retarded, the follicular basal lamina may trap large molecules (for example some proteoglycans) that are synthesized by granulosal cells and oocytes in the follicular fluid. The molecular mass cut off is calculated to be $100-850 \mathrm{kDa}$ based upon comparisons of the composition of follicular fluid with that of plasma (Anderson et al., 1976). It is not known whether the size of material that can cross the follicular basal lamina changes during the course of follicular development, particularly before and after antrum formation.

The molecular weight cut off of the follicular basal lamina is considerably larger than most growth factors. It is probably for this reason that many authors have assumed that growth factors can readily move from the thecal layer to the membrana granulosa, and vice versa. However, the follicular basal lamina could be a barrier to the movement of growth factors from theca interna to membrana granulosa, and vice versa. This is due to the nature of growth factors (for example fibroblast growth factor 2), or their binding proteins (for example follistatin, insulin-like growth factor binding factor 5), to bind avidly to extracellular matrix components, especially heparan sulphate proteoglycans. It is also possible that the follicular basal lamina serves as a reservoir of attached growth factors. Thus, in contrast to the wealth of literature on the production of growth factors and the expression of their receptors, and the notion that thecal and granulosal cells signal each other via growth factors, there is scant evidence that this can actually occur.

We have estimated that the surface area of the bovine follicle doubles nineteen times during follicular development, implying that continuous remodelling of the follicular basal lamina occurs (van Wezel and Rodgers, 1996). We hypothesized that the composition of the follicular basal lamina is altered during follicular development, particularly at the time when follicular fluid accumulates to form an antrum, and during follicular atresia. Immunolocalization studies have demonstrated the presence of collagen IV (Bagavandoss et al.; 1983; Kaneko et al., 1984; Palotie et al., 1984), laminin (Wordinger et al., 1983; Bagavandoss et al., 1983; Palotie et al., 1984; Leu et al., 1986; Christiane et al., 1988; Yoshinaga-Hirabayashi et al., 1990; Leardkamolkarn and Abrahamson, 1992; Fröjdman et al., 1995), and fibronectin (Bagavandoss et al., 1983; Yoshimura et al., 1991; Figueiredo et al., 1995) in the follicular basal laminae of antral follicles. However, none of these studies has differentiated between the different isoforms of any of these components, except for one study that compared the localisation of $\alpha 1$ versus $\beta 1-\gamma 1$ laminin in the fetal mouse ovary (Fröjdman et al., 1995). Other studies using western and northern blotting identified the expression of a few of the subtypes of collagen and laminin (Zhao and Luck, 1995; Iivanainen et al., 1995) but did not specifically localize these components to the follicular basal lamina; this is important as there are other basal laminae in follicles, such as those associated with blood vessels.

In recent studies of the bovine follicle (Fig. 1), we found that laminin $\alpha 1$ chain was present in the follicular basal lamina at all stages of follicular development, while laminin $\alpha 2$ chain was present only in atretic antral follicles and a few healthy antral follicles and absent from primordial and growing preantral follicles (van Wezel et al., 1998). The laminin $\beta 2$ chain was present in the follicular basal lamina of follicles of all stages, but the laminin $\beta 1$ chain was detected only in the basal lamina of large preantral follicles. Staining for laminin $\alpha 1, \beta 2$ or $\gamma 1$ chains appeared to increase in intensity from the preantral to healthy antral stages, and the basal lamina of atretic antral follicles appeared thicker but stained less intensely than that of healthy antral follicles. The basal laminae of the thecal 
Follicular basal lamina Laminin chains

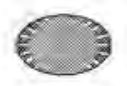

$\alpha 1$ B2 $\gamma 1$

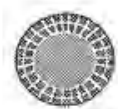

$\alpha 1$ $\beta 1, \beta 2$ $\gamma 1$

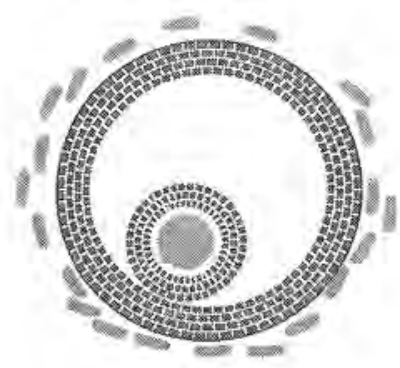

$\alpha 1$

$\beta 2$

$\gamma 1$

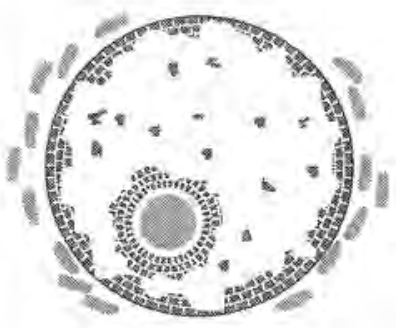

$a 1, a 2$

$\beta 2$

$\gamma 1$

Fig. 1. The laminin chains identified in the follicular basal lamina of bovine follicles (summarized from van Wezel et al., 1998). Follicles from left to right represent primordial, preantral, healthy antral and atretic antral follicles.

vasculature stained positively for laminin $\beta 1$ and $\beta 2$ chains, whereas the laminin $\gamma 1$ chain localized more generally throughout the theca in areas that do not have a recognized conventional basal lamina. The follicular basal lamina of almost all primordial and preantral follicles was postive for all of the type IV collagen chains $\alpha 1-\alpha 6$. However, only a proportion of antral follicles had a basal lamina immunopositive for the type IV collagen chains $\alpha 3, \alpha 4$ or $\alpha 5$. In addition to staining the follicular basal lamina, $\alpha 1 \alpha_{2}$ was also present in the theca and not associated with a structural basal lamina (Rodgers ef al., 1998).

Examination of the bovine follicular basal lamina by electron microscope has shown that it is a single layer closely associated with the granulosal cells in primordial follicles (van Wezel and Rodgers, 1996). The follicular basal lamina of a number of larger follicles is composed of many layers of basal lamina material forming a branching network (Rodgers et al., 1995). This finding is consistent with the notion that the basal lamina is shed and replaced by a newly synthesized basal lamina closer to the granulosal cells as the follicle grows. These observations and that of different laminin and collagen type IV isoforms at different stages of follicular development (see above) allow us to suggest that the follicular basal lamina is continually remodelled during follicular development. On the basis of the knowledge of other basal laminae we suggest that these changes in the follicular basal lamina are related key changes during follicular development. These changes could include the formation of follicular fluid or the migration, proliferation or differentiation of the granulosal cells.

We have also found that larger antral follicles either have a single layer of basal lamina, like that of primordial follicles, or have multilayers that form a branching network. The latter have vesicles attached to the basal lamina material not immediately adjacent to the cell surface (Rodgers et al, 1995). Vesicles have been observed rarely in other basal laminae but have been observed in the camel kidney (Safer and Katchburian, 1991). The significance of these vesicles, or of the two phenotypes of follicular basal lamina, is not clear yet.

The cellular origin of the follicular basal lamina is a contentious issue (see van Wezel and Rodgers, 1996). Concerning the laminin component of the follicular basal lamina, the $\gamma 1$ chain but not $\beta 1$ chain was expressed by granulosal cells as detected by northern blot analysis, and this is consistent with the present study localizing the $\gamma 1$ but not $\beta 1$ laminin chain to the follicular basal lamina of antral follicles. Furthermore, a previous immunoelectron study in the rat ovary (Leardkamolkarn and Abrahamson, 1992) localized laminin to Call-Exner bodies, which are similar in ultrastructure to basal lamina and have been observed within the membrana granulosa of follicles in vizo (cow: van Wezel et al., 1999a; rabbit: Gosden et al., 1988). Laminin was also localized intracellularly in both granulosal and thecal cells, but this latter observation may represent degradation rather than synthesis. We have also shown that granulosal cells cultured under anchorage-independent conditions produce a basal lamina, collagen type IV (Rodgers et al., 1995) 
and fibronectin (Rodgers et al., 1996). All of these studies suggest that the granulosal cells are capable of secreting many of the components of a basal lamina. The contribution of the theca in larger follicles, or indeed the stroma surrounding preantral follicles, to the production of the follicular basal lamina is not known. In other systems, it is predominantly epithelial rather than stromal cells that synthesize basal lamina components, although in some tissues both cell types make a contribution (Timpl and Dziadek, 1986). The thecal compartment of antral follicles has been shown by northern blot analyses to express laminin $\beta 1$ and $\gamma 1$ chains (Zhao and Luck, 1995). Our recent observations showing laminin $\beta 1$ in the thecal vasculature and undetectable in the follicular basal lamina of antral follicles (van Wezel et al., 1998) indicate that the thecal expression of $\beta 1$ is not necessarily a contribution to the follicular basal lamina. Similarly, laminin $\gamma 1$ was found widely distributed in the theca and, although it is present in the follicular basal lamina, expression in the theca cannot be considered as proof that the theca contributes laminin $\gamma 1$ to the follicular basal lamina. However, it remains possible that in vivo, the follicular basal lamina requires a contribution from both the granulosal cells and the stromal or thecal cells.

\section{'Thecal Matrix'}

Immunostaining for laminin $\gamma 1$ chain or EHS $(\alpha 1 \beta 1 \gamma 1)$ laminin has been observed in bovine follicles throughout the theca interna (van Wezel et al., 1998). This staining was extracellular and in areas where there are no conventional basal laminae, such as those of blood vessels, We have also observed this pattern of staining using antibodies to some types of collagen IV (Rodgers et al., 1998). In other species (rat: Bagavandoss et al., 1983; Leardkamolkarn and Abrahamson, 1992; mouse: Fröjdman et al., 1995) and in the interstitial tissue of developing gonads (Fröjdman et al., 1989, 1992a,b, 1993, 1995; Smith and MacKay, 1991), similar immunostaining patterns have been obtained using antibodies to EHS laminin. At the level of the electron microscope, fragments of basal laminalike, electron-dense material have been observed in the theca interna in sheep (O'Shea et al., 1978), rats (Leardkamolkarn and Abrahamson, 1992) and cows (see Fig. 1 in Rodgers et al., 1986). It is likely, though not proven, that collagen IV and some of the laminin chains are present in these fragments of basal lamina-like material in the theca. The origins and functions of this 'thecal matrix' are not known. It is possible that they are involved in the vascularization and the formation and expansion of the theca that occurs during follicular development.

\section{Follicular Epithelium}

The membrana granulosa is multilayered, and there is a persistent coordinated interaction between the granulosal cells and the oocyte and theca (Buccione et al., 1990). The fate of the granulosal cells is either redifferentiation at the time of ovulation to form a mesenchymal cell type, the luteal cells, or death of the granulosal cells and destruction of the membrana granulosa in follicular atresia. Before luteinization, the granulosal cells are regarded as an epithelial or epithelioid cell type (see Hirshfield, 1991).

Quite a lot is known about other epithelia, such as the epidermis of skin and the luminal epithelium of the gut. Both of these epithelia lie on a basal lamina and are highly structured. Subpopulations of cells are located in specific regions of the epithelia. There is a population of stem cells and, at a distance from these, a population of well differentiated cells (Stenn, 1983). In the gut crypt, there is also a separate population of more rapidly dividing cells between the stem cells and differentiated cells (Potten and Loeffler, 1990). The membrana granulosa of ovarian follicles also lies on a basal lamina (van Wezel et al., 1998) and there is some indication that granulosal cells in different regions of the membrana granulosa have different shapes (Marion et al., 1968) and biochemical properties (Amsterdam et al., 1975; Bortolussi et al., 1977; Zoller and Weisz, 1978, 1979; Dunaif et al., 1982; Zlotkin et al., 1986; Tabarowski and Szoltys, 1987; Salustri et al., 1992).

In contrast to the other epithelial cell types, very little has been discovered about the membrana 
Small follicles

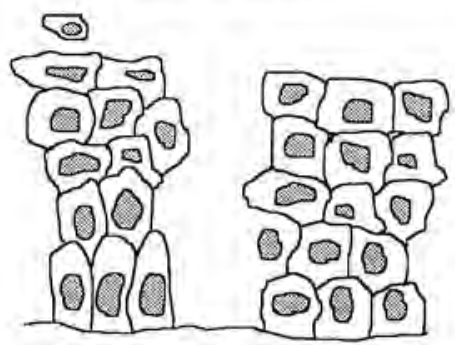

Large follicies

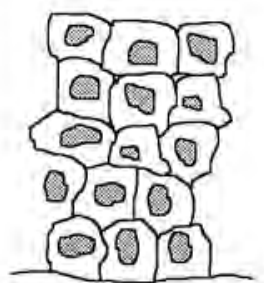

Fig. 2. The structure of the membrana granulosa observed in bovine small $(<5 \mathrm{~mm})$ and large $(>5 \mathrm{~mm})$ antral follicles. Some smaller follicles have a zone of columnar cells adjacent to the follicular basal lamina, a zone of rounded cells closer to the antrum, and a zone of flattened granulosal cells immediately adjacent to the antrum; other cells have rounded basal cells. Larger follicles have rounded basal granulosal cells.

granulosa as an epithelium. Its overall structure has not been reported, particularly as a function of follicular development, nor has the location of the dividing cells and the location of differentiated cells, if there are any. The membrana granulosa is also more complex than other epithelia for a number of reasons. First, it expands from a single to a multi-layered epithelium as the follicle grows. In the transition from pre- to post-antral follicles, the amount of fluid traversing the epithelium changes considerably. The epithelium expands laterally with time as the follicle grows. Total destruction of the epithelium occurs as the follicle becomes atretic, and death of the granulosal cells is one of the first indicators of follicular atresia. Thus, not only is the follicular epithelium poorly understood, it is considerably complex. Recently, we have undertaken to study the cellular biology of the membrana granulosa.

Changes occur in the membrana granulosa and its environment during follicular growth. These changes include the formation of an antrum, a net increase in the surface area of the follicle (19 doublings to form an $18 \mathrm{~mm}$ bovine follicle, calculated from van Wezel and Rodgers, 1996), and a net increase in the number of granulosal cells (estimated at 21 doublings, if $40 \times 10^{6}$ granulosal cells were present as reported by McNatty et al., 1984 - see van Wezel and Rodgers, 1996). The net increase in the number of cells is related to the extent of cell division and loss of cells via apoptosis or terminal differentiation (van Wezel et al, 1999b). The net increases in both cell numbers and surface area have important ramifications for the number of layers of cells in the membrana granulosa. For example, if the cell numbers double 21 times and the surface area doubles 19 times (see van Wezel and Rodgers, 1996), it is predicted that cell layers in the membrana granulosa would increase from one layer, as in primordial follicles, to four $\left[(21-19)^{2}\right]$ layers. In a recent study, we found considerable variation in the numbers of layers per follicle (van Wezel et al., 1999c), and this is consistent with a reported variation in the number of granulosal cells obtained from follicles of the same size (McNatty et al,, 1979). On the basis of these observations and the variation in basal cell shapes (columnar or rounded) in the smaller follicles $(\leqslant 5 \mathrm{~mm}$ ) (see below), we suggest that the rate of granulosal cell proliferation and maturation is not tightly or coordinately regulated with the timing or rate of antrum formation or to follicular expansion. Thus, follicle size is not necessarily a good indication of follicle maturation.

We have found three structurally distinct zones in the membrana granulosa of many small bovine antral follicles: a zone of columnar cells adjacent to the follicular basal lamina, a zone of rounded cells closer to the antrum, and a zone of flattened granulosal cells immediately adjacent to the antrum (Fig 2). The presence of columnar and rounded cells has been described in a range of species, while the layer of flattened cells closest to the antrum was mentioned in the literature thirty years ago (Marion et al., 1968) but has been ignored in more recent literature. In a recent study (van Wezel et al., 1999c), we have demonstrated that the structure of the membrana granulosa varies 
between follicles: distinct layers of columnar, rounded and flattened cells were only found in small follicles ( $\leq 5 \mathrm{~mm}$; ovulation is from follicles $\geq 10 \mathrm{~mm}$; Staigmiller and England, 1982), and larger follicles contained predominantly rounded cells throughout the membrana granulosa (Fig. 2). It is therefore possible that there is a developmental progression from columnar to rounded cells in the basal zone of the follicle as the antral follicle enlarges.

The issue of whether cells in different regions of the membrana granulosa (basal to antral) are at different stages of differentiation is complex. Cells tend to differentiate in G0 and by far the greatest proportion of non-dividing cells was found in the most basal and most antral layers of bovine antral follicles (see below). Therefore, it would appear that cells replicate in the middle zones of the membrana granulosa in antral follicles and then migrate in either of two opposite directions: towards the antrum or towards the basal lamina. As they migrate and spend longer in G0, it is probable that their phenotype and hence pattern of gene expression change. The nature of the differentiation has still to be addressed. Certainly many authors recognize expression of cytochrome P450 aromatase and oestradiol production as markers of differentiation, but there may be other specialized functions that granulosal cells undertake, particularly at the time of antrum formation.

It has been suggested that cells in the basal zone are more differentiated than are the antrally situated cells of the membrana granulosa (see Amsterdam, 1987). These suggestions arose from numerous studies localizing LH receptors (Amsterdam and Rotmensch, 1975, Bortolussi et al., 1977), steroidogenic enzymes (Zoller and Weisz, 1978; 1979; Zlotkin et al., 1986; Tabarowski and Szoltys, 1987), or housekeeping enzymes (Zoller and Weisz, 1979; Zoller and Enelow, 1983) in the follicle of a number of species. The amounts of these enzymes and receptors were apparently higher (usually about double) in the basal zone than in the antral regions of the membrana granulosa. Unfortunately many of these studies did not measure the receptors/enzymes on a per cell basis, but rather the level of staining per unit area of the membrana granulosa. In bovine antral follicles we have observed that columnar basal cells were more compact than the rounded cells found in the middle or antral zones. This difference in the level of 'cellularity' between basal and antral zones has not previously been considered, and it may be a cause of the apparent reduced staining for receptors or enzymes of the antral zone observed in many studies. We therefore consider that a reanalysis of this area is warranted.

Clearly the issues of differentiation of cells in the membrana granulosa are complex and still unresolved. However, we propose that the membrana granulosa is more similar to other epithelia than previously recognized. The shape of the granulosal cells in different zones is comparable to skin epidermis, where cells in the 'basal layer' are columnar, cells in the 'spinous layer' (in the suprabasal position) are rounded, and the cells that are furthest from the epithelial basal lamina in the 'granular', 'transitional', and 'horny' layers are increasingly flattened (Stenn, 1983). Furthermore, we propose that there is a spatial progression in the membrana granulosa from stem cells (see below) near the basal lamina to terminally differentiated cells near the antrum which are more flattened and slough from the membrana granulosa into the lumen (van Wezel et al., 1999b). This is also similar to skin, where the stem cells are located in the basal layer and the terminally differentiated keratinocytes are furthest from the basal lamina and are desquamated. However, whereas cell proliferation in the epidermis is limited to cells in the basal layer (Stenn, 1983), cell division in the membrana granulosa is more common in the middle regions (see below). This could be similar to the luminal epithelium of gut, in which the stem cells and the rapidly dividing cells are spatially distinct (Potten and Loeffler, 1990). One important difference between the membrana granulosa and the skin epidermis is that the membrana granulosa expands laterally as the follicular antrum grows. Thus in addition to cellular movement in basal-antral directions, movement in a sideways direction could also occur. The degree of this will depend upon the rate of cellular replication versus the rate of follicular antrum expansion.

\section{Granulosal Stem Cells}

In some tissues, cell division is carried out exclusively by stem cells. True or even committed stem cells are totipotent or pluripotent, and they can divide in vivo without contact inhibition or in vitro 
without the need for anchorage. We have argued that granulosal cells divide in vivo without contact inhibition, at least during the preantral stages when the cells are in very close physical contact with each other. In a recent study of antral follicles, most of the dividing cells were found in the middle layers of the membrana granulosa (van Wezel et al., 1999c). Thus, in vivo, granulosal cells can divide and are not inhibited from doing so by contact with adjacent cells, In vitro we have demonstrated that a proportion of granulosal cells can divide in soft agar or methycellulose solution, neither of which provide anchorage (Lavranos and Rodgers, 1994; Lavranos et al., 1994, 1996; Rodgers et al., 1995). On the basis of these observations, we have postulated that there is a population of granulosal stem cells (Lavranos and Rodgers, 1994; Lavranos et al., 1994, 1996; Rodgers et al., 1995).

It is not known where the granulosal stem cells reside in the membrana granulosa. Cell division is not always carried out by stem cells alone. In the luminal epithelium of the gut crypt, a population of cells that are spatially distinct from the stem cell subpopulation has been described; these are more differentiated and more rapidly dividing. In a recent study of the membrana granulosa of bovine antral follicles, most of the mitotic figures were observed in the middle regions, although such figures were present throughout the membrana granulosa and theoretically any of these could be the stem cell subpopulation (van Wezel ct al., 1999c). However, on the basis of our observation that $19 \%$ of colonies grown from bovine granulosal cells under anchorage-independent conditions produced a basal lamina like material (Rodgers et al., 1996), we suggest that in vivo at least some granulosal cells with properties of stem cells are located close to the follicular basal lamina.

\section{Conclusion}

Most studies on 'folliculogenesis' have focused on the hormones and growth factors involved. However, in many other organ systems, structural studies similar to our recent investigations of the membrana granulosa were undertaken decades ago. We have also discussed the follicular basal lamina and thecal matrix. Clearly there are many important and informative studies to be done in both of these areas, and of course there are many other areas of discovery within the follicle. We have also highlighted areas where we consider the literature to be too superficial in its assumptions on how follicles function. In conclusion, the study of the cellular biology of the ovarian follicle is not as advanced as that of many other organs but promises to hold many exciting discoveries.

The authors would like to acknowledge the support of the National Health and Medical Research Council of Australia, Flinders University and Flinders Medical Research Foundation.

\section{References}

Amsterdam A and Rotmensch S (1987) Structure-function relationships during granulosa cell differentiation Endocrine Reviens 8 309-337

Amsterdam A, Koch Y, Lieberman ME and Lindner HR (1975) Distribution of binding sites for human chorionic gonadotropin in the preovulatory follicle of the rat fournal of Cell Biology $67894-900$

Amsterdam A, Rotmensch S, Furman A, Venter EA and Vlodavsky I (1989) Synergistic effect of human chorionic gonadotrophin and extracellular matrix on it vitro differentiation of human granulsoa cells: progesterone production and gap junction formation Endocrinology 124 1956-1964

Andersen MM, Kroll J, Byskov AG and Faber M (1976) Protein composition in the fluid of individual bovine follicles Journal of Reproduction and Fertility 48 109-118

Bagavandoss P, Midgley AR, Jr and Wicha M (1983) Developmental changes in the ovarian follicular basal lamina detected by immunofluorescence and electron microscopy foumal of Histochemistry and Cytochemistry 31 633-640

Bellin ME and Ax RL (1984) Chondroitin sulfate: an indicator of atresia in bovine follicles Endocrinology $114428-434$

Bortolussi M, Marini G and Dal Lago A (1977) Autoradiographic study of the distribution of LH (HCG) receptors in the ovary of untreated and gonadotrophin-primed immature rats Cell and Tissue Research 183 329-342

Buccione R, Schroeder AC and Eppig JJ (1990) Interactions between somatic cells and germ cells throughout mammalian oogenesis Biology of Reproduction 43 543-547

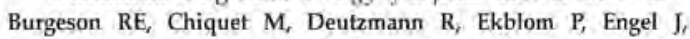
Kleinman H, Martin GR, Meneguzzi G, Paulsson M, Sanes J, Timpl R, Tryggvason K, Yamada $Y$ and Yurchenco PD (1994) A new nomenclature for the laminins Matrix Biology 14 209-211

Christiane Y, Demoulin A, Gillain D and Leroy F (1988) Laminin and type III procollagen peptide in human preovulatory follicular fluid Fertility and Sterility 50 48-51 
Dunaif AE, Zimmerman EA, Friesen HG and Frantz AG (1982) Intracellular localization of prolactin receptor and prolactin in the rat ovary by immunocytochemistry Endocrinology 110 1465-1471

Engvall E (1993) Laminin variants: why, where and when? Kidney International 43 2-6

Figueiredo JR, Hulshof SC], Thiry M, Van Den Hurk R, Bevers MM, Nusgens B and Beckers JF (1995) Extracellular matrix proteins and basement membrane: their identification in bovine ovaries and significance for the attachment of cultured preantral follicles Theriogenology 43 845-858

Fröjdman K, Paranko J, Kuopio T and Pelliniemi LJ (1989) Structural proteins in sexual differentiation of embryonic gonads International Journal of Developmental Biology 33 , 99-103

Fröjdman K, Malmi R and Pelliniemi LJ (1992a) Lectin-binding carbohydrates in sexual differentiation of rat male and temale gonads Histochemistry $97469-477$

Fröjdman K, Paranko J, Virtanen I and Pelliniemi LJ (1992b) Intermediate filaments and epithelial differentiation of male rat embryonic gonad Differentiation 50 113-123

Fröjdman K, Paranko J, Virtanen I and Pelliniemi LJ (1993) Intermediate filament proteins ' ${ }^{\prime}$ and epithelial differentiation in the embryonic ovary of the rat Differentiation 55 47-55

Fröjdman K, Ekblom P, Sorokin L, Yagi A and Pelliniemi J (1995) Differential distribution of laminin chains in the development and sex differentiation of mouse internal genitalia International Joumal of Developmental Biology 39 335-344

Gosden RG, Hunter RHF, Telfer E, Torrance C and Brown N (1988) Physiological factors underlying the formation of ovarian follicular fluid Joumal of Reproducfion and Fertility 82 813-825

Grimek HJ (1984) Characteristics of proteoglycans isolated from small and large bovine ovarian follicles Biology of Reproduction $30397-409$

Hay ED (1991) Cell Biology of Extracellular Matrix (2nd Edn) Plenum Press, New York

Hirshfield AN (1991) Development of follicles in the mammalian ovary International Review of Cy/tology 124 43-101

livanainen A, Sainio K, Sariola H and Tryggvason KB (1995) Primary structure and expression of a novel human laminin alpha-4 chain FEBS Letters 365 183-188

Kaneko Y, Hirakawa S, Momose K and Konomi H (1984) Immunochemical localization of Type I, III, IV and V collagens in the normal and polycystic ovarian capsules Actr Obsietrica Gynaecologica japonica 36 -2473-2474 (Abstract)

Lavranos TC and Rodgers RJ (1994) An assay of tritiated thymidine incorporation into DNA by cells cultured under anchorage-independent conditions Analytical Biochemistry $223325-327$

Lavranos TC, Rodgers HF, Bertoncello I and Rodgers RJ (1994) Anchorage-independent culture of bovine granulosa cells: the effects of basic fibroblast growth factor and dibutyryl CAMP on cell division and differentiation Experimental Cell Research 211 245-251

Lavranos TC, O'Leary PC and Rodgers RJ (1996) Effects of insulin-like growth factors and binding protein-1 on bovine granulosa cell division in anchorage-independent culture Journal of Reproduction and Fertility $106221-228$

Leardkamolkarn V and Abrahamson DR (1992) Immunoelectron microscopic localization of laminin in rat ovarian follicles Anatomical Record 233 41-52

Leu FJ, Engvall E and Damjanov I (1996) Heterogeneity of basement membranes of the genitourinary tract revealed by sequential immunofluorescence staining with monoclonal antibodies to laminin Journal of Histochenistry and Cytochemistry $34483-489$

Luck MR (1994) The gonadal extracellular matrix Oxford Reviews in Reproductive Biology 16 33-85

McNatty K, Smith DM, Makris A, Osathanondh R and Ryan KJ (1979) The microenvironment of the human antral follicle: interrelationships among the steroid levels in antral fluid, the population of granulosa cells, and the status of the oocyte in vivo and in vitro: Journal of Clinical Endocrinology and Metabolism $49851-860$

McNatty KP, Heath DA, Lun S, Fannin JM, McDiarmid JM and Henderson KM (1984) Steroidogenesis by bovine theca interna in an in vitro perifusion system. Biology of Reproduction $30159-170$

Marion GB, Gier HT and Choudary JB (1968) Micromorphology of the bavine ovarian follicular system. journal of Animal Science 27 451-465

Noakes PG, Gautam M, Mudd J, Sanes JR and Merlie JP (1995) The renal glomerulus of mice lacking s-laminin/laminin B2: nephrosis despite molecular compensation by laminin 81 Nature Gentetics $10400-406$

O'Shea JD, Cran DG, Hay MF and Moor RM (1978) Ultrastructure of the theca interna of ovarian follicles in sheep Cell and Tissue Research $187473-478$

Palotie A, Peltonen L, Foidart J-M and Rajaniemi H (1984) Immunohistochemical localization of basement membrane components and interstitial collagen types in preovulatory rat ovarian follicles Collagen Related Research $4279-287$

Paulsson M (1992) Basement membrane proteins: structure, assembly, and cellular interactions Critical Reviews in Biochemistry and Molecular Biology 27 93-127

Potten CS and Loeffler M (1990) Stem cells: attributes, cycles, spirals, uncertainties and pitfalls: lessons for and from the crypt Development 110 1001-1019

Richardson MC, Davies DW, Watson RH, Dunsford ML, Inman CB and Masson GM (1992) Cultured human granulosa cells as a model for corpus luteum function: relative roles of gonadotrophin and low density lipoprotein studied under defined culture conditions Human Reproduction 7 12-18

Rodgers HF, Lavranos TC, Vella CA and Rodgers RJ (1995) Basal lamina and other extracellular matrix produced by bovine granulosa cells in anchorage-independent culture Cell Tissue Research $282463-471$

Rodgers RJ, Rodgers HF, Hall PF, Waterman MR and Simpson ER (1986) Immunolocalization of cholesterol side-chaincleavage cytochrome $\mathrm{P}-450$ and $17 \alpha$-hydroxylase cytochrome $\mathrm{P}-450$ in bovine ovarian follicles fournal of Reproduction and Fertility 78 627-638

Rodgers RJ, Vella CA, Rodgers HF, Scott K and Lavranos TC (1996) Production of extracellular matrix, fibronectir and steroidogenic enzymes, and growth of bovine granulosa cells in anchorage-independent culture. Reproduction Fertility and Development $8249-257$

Rodgers HF, Irvine CM, van Wezel IL, Lavranos $\mathrm{TC}_{\text {r }}$ Luck MR, Sao Y, Ninomiya $Y$ and Rodger's RJ (1998) Distribution of the $\alpha 1$ to a6 chains of Type IV collagen in bovine follicles Biology of Reproduction 59 1334-1341

Safer AM and Katchburian I (1991) Unusual membrane-bound 
bodies in the basal lamina of the uriniferous tubules of the camel Camelis dromedarius. Freeze-fracture and ultrathinsection study Acta Anatomica 140 156-162

Salustri A, Yanagishita M, Underhill CB, Laurent TC and Hascall VC (1992) Localization and synthesis of hyaluronic acid in the cumulus cells and mural granulosa cells of the preovulatory follicle Developmental Biology 151 541-551

Smith C and MacKay S (1991) Morphological development and fate of the mouse mesonephros Journal of Anatomy 174 171-184

Staigmiller RB and England BG (1982) Folliculogenesis in the bovine Theriogenology 17 43-52

Stenn KS (1983) The Skin. In Histology: Cell and Tissue Biology (2nd Edn) pp569-606 Ed. L Weiss. Elsevier Science, New York

Tabarowski Z and Szoltys M (1987) Histochemical localization of $\Delta^{5}-3 \beta-H S D H$ activity in preovulatory rat follicles Folia Histochemistry Cytobiology 25 149-154

Timpl R and Dziadek M (1986) Structure, development and molecular pathology of basement membranes International Reviews in Experimental Pafhology 29 1-112

van Wezel II and Rodgers RJ (1996) Morphological characterization of bovine primordial follicles and their environment in vivo, Biology of Reproduction 55 1003-1011

van Wezel Il, Rodgers HF and Rodgers RJ (1998) Differential localisation of larninin chains in bovine follicles foumal of Reproduction and Fertility 112 267-278

Watt FM (1986) The extracellular matrix and cell shape Trends in Biochemistry Science $11482-585$

van Wezel IL, Rodgers HF, Saod Y, Ninomiya $Y$ and Rodgers RJ (1999a) Ultrastructure and composition of Call-Exner bodies in bovine follicles Cell Tissue Research (in press)

van Wezel IL, Dbarmarajan AM, Lavranos TC and Rodgers RJ (1999b) Evidence for alternative pathways of granulosa cell death in healthy and slightly atretic bovine antral follicles Endocrinology 140 (in press)

van Wezel IL, Krupa M and Rodgers RJ (1999c) Development of the membrana granulosa of bovine antral follicles: structure, location of mitosis and pyknosis, and immunolocalization of involucrin and vimentin Reproduction fertility and Development (in press)

Wordinger RJ, Rudick VL and Rudick MJ (1983)
Immunohistochemical localization of laminin within the mouse ovary Joumal Experimental Zoology 228 141-143

Yoshimura Y, Okamoto T and Tamura T (1991) Localization of fibronectin in the bovine ovary Animal Science Technology $62529-532$

Yanagishita M, Rodbard V and Hascall VC (1979) Isolation and characterization of proteoglycans from porcine follicular fluid Journal Biological Chemistry 254 911-920

Yoshinaga-Hirabayashi T, Ishimura K, Fujita $\mathrm{H}$, Kitawaki $\mathrm{J}$ and Osawa X (1990) Immunocytochemical localization of aromatase in immature rat ovaries treated with PMSG and hCG, and in pregnant rat ovaries Histochemistry 93 223-228

Yurchenco PD and Schittny JC (1990) Molecular architecture of basement membranes FASEB Journal 4 1577-1590

Zhao $\mathrm{Y}$ and Luck MR (1995) Gene expression and protein distribution of collagen, fibronectin and laminin in bovine follicles and corpora lutea Journal of Reproduction and Fertility 104 115-123

Zhou J, Ding M, Zhao Z and Reeders ST (1994) Complete primary structure of the sixth chain of human basement membrane collagen, a6(IV) Journal Biological Chemistry 269 13193-13199

Zlotkin T, Farkash Y and Orly J (1986) Cell-specific expression of immunoreactive cholesterol side-chain cleavage cytochrome $\mathrm{P}-450$ during follicular development in the rat ovary Endocrinology 119 2809-2820

Zoller LC and Enelow R (1983) A quantitative histochemical study of lactate dehydrogenase and succinate dehydrogenase activities in the membrana granulosa of the ovulatory follicle in the rat Histochemical fournal 15 1055-1064

Zoller LC and Weisz J (1978) Identification of cytochrome P-450, and its distribution in the membrana granulosa of the preovulatory follicle, using quantitative cytochemistry Endocrinology 103 310-313

Zoller LC and Weisz J (1979) A quantitative cytochemical study of glucose-6-phosphate dehydrogenase and $\Delta^{5}-3 \beta$ hydroxysteroid dehydrogenase activity in the membrana granulosa of the ovulable type of follicle in the rat Histochemistry 62 125-135 